\title{
Dinámica de casa y reproducción social en la hidalguía gallega durante el siglo XVIII ${ }^{1}$
}

\author{
antonio Presedo Garazo \\ Instituto de Estudios Gallegos «Padre Sarmiento" (CSIC-XuGa) \\ Santiago de Compostela
}

\begin{abstract}
RESUMEN
Durante el siglo XVIII, el estamento nobiliario gallego - y dentro de éste, principalmente la hidalguia - ha alcanzado el cenit de su capacidad para controlar una parte considerable de los resortes políticos y económicos del antiguo reino de Galicia; $y$ de hecho, no cabe la menor duda de que se asiste al auge de la "civilización de los pazos". En buena medida, estos éxitos no se pueden comprender en toda su complejidad sin atender a las pautas seguidas por el grupo a la hora de diseñar su reproducción social, muy condicionada por un modelo característico en el que la casa ejerce como centro vertebrador. A lo largo de las siguientes páginas se pretende explicar,

precisamente, cuáles son los elementos intrínsecos a dicho modelo de reproducción social, y asimismo qué significado concreto - material e inmaterial - tiene la casa para dicho estamento.
\end{abstract}

PALABRAS CLAVE:

Nobleza, hidaiguia, casa, reproducción social, dinámica centrípeta, modelo sucesorio, politica matrimonial.

\begin{abstract}
During the XVII th century, the Galician noble class - and principally the hidaiguia - has reached the highest competence to control a considerable part of the political and economic means of the old Galician Kingdom, and, as a matter of fact, there can be no doubt that we attend to a period of prosperity of the 'pazos' civilization". To a great extent, this success can't be completely understood without paying attention to the models followed by this social group when it comes to planning their social reproduction, where the household is the essential structure. In the next pages we try to explain this social reproduction model's inherent elements, and, in the same way, the specific significance ( $p$ hysical and inmaterial) of the househola'.
\end{abstract}

\section{KEYWORDS:}

Nobility, hidalguia, household, social reproduction, centripetal dynamic, inheritance model, matrimonial policy.

' Este trabajo ha sido realizado en el marco del proyecto de investigación: "Los pazos de Galicia: Hidalgos y señores en el Antiguo Régimen" (XGPS 2002.09). Una prımera versión del mismo fue presentada como comunicación al $2 .^{\circ}$ Coloquio sobre História das Élites celebrado en Lisboa el pasado mes de noviembre de 2003, y organizado por el Instituto de Ciências Socias de la Universidade de Lisboa. 


\section{INTRODUCCIÓN: LA HIDALGUIA GALLEGA EN EL SIGLO XVIII. UN GRUPO SOCIAL DOMINANTE Y HETEROGÉNEO}

Pocos sectores sociales de la Galicia del Antiguo Régimen han suscitado, durante los últimos años, un interés tan evidente entre los historiadores gallegos que se han aproximado a la historia de las elites, como la categoría nobiliaria de la hidalguía. Un simple repaso a la media docena de memorias de licenciatura y tesis de doctorado especializadas en dicha temática histórica, dirigidas por los catedráticos Ramón Villares Paz y Pegerto Saavedra Fernández, y defendidas en la Universidad de Santiago de Compostela desde tres lustros atrás hasta nuestros días, no hace sino confirmar este presupuesto inicial de nuestra reflexión ${ }^{2}$.

Lo cierto es que no podía ser de otro modo, si tenemos en cuenta que a mediados del siglo XVIII, coincidiendo con el momento en que la Monarquía llustrada decidió acometer el gran reto logístico de catastrar sus dominios castellanos, con objeto de valorar la posibilidad de aplicar el cobro de una contribución única a sus súbditos, el contingente de población nobiliaria había llegado a alcanzar una representatividad nada desdeñable que rondaba entre un $3,2 \%$ de los vecinos y un $5 \%$ de la población residente dentro de los límites geográficos comprendidos por el antiguo reino de Galicia $^{3}$, que alcanzaba por entonces, en conjunto, 1.299 .312 habitantes ${ }^{4}$.

2 Cf. Leirós de la Peña, Paz: La Casa de Fontefiz (Contribución al estudio de la hidalguía gallega), Santiago de Compostela, 1986, memoria de licenciatura inédita; DomingUEZ CASTRO, Luis: Viños, viñas e xentes do Ribeiro. Economia e patrimonio familiar, 1810-1952, Vigo, 1992; Migués RodRiguez, Vítor Manuel: A fidalguía galega: un brebe enxergar histórico através da Casa de San Fiz de Asma e agregadas no Antigo Réxime, Santiago de Compostela, 1997, y A terra, as pousas e os vinculeiros. A fidalguia galega na Época Moderna, Sada, 2002; PRESEdo GARAzo, Antonio: Os devanceiros dos pazos. Economía e estratexias sociais da pequena fidalguia na Galicia interior (ss. XVI-XVIII), Santiago de Compostela, 1997, y Dueños y señores de casas, torres y pazos, 1500-1900 (Contribución al estudio de la fidalguia gallega), 2 vols., Santiago de Compostela, 2001, tesis doctoral inédita; y IGLESIAS BLANCO, Anastasio Santos: "La casa de Junqueras en el siglo XVill y XIX. Contribución al estudio de las economías hidalgas", Obradoiro de Historia Moderna [en adelante OHM], 12 (2003), pp. 247-270. Vid. además las síntesis recientes de SaAvedra Fernandez, Pegerto: «Formación, consolidación e influencia social e cultural da fidalguía, SS. XVI-XVIII», in VV.AA.: Galicia fai dous mil anos. O feito diferencial galego. I, Historia, Santiago de Compostela, 1997, pp. 123-156, y "A vida cotiá da îidalguía pacega", in VV.AA.: Un percorrido pola Galicia cotiá, Santiago de Compostela, 1998, pp. 373-396; VILLARES PAZ, Ramón: "La nobleza gallega en los siglos XVI al XIX: la hegemonía de la hidalguía de pazo", in IGLESIAS, Carmen (dir.): Nobleza y sociedad en la España Moderna, Oviedo, 1999, t. 3, pp. 31-63; MIgués Rodríguez, V. M.: “Una visión en panorámica de la hidalguía gallega", OHM, 9 (2000), pp. 301-323; y PRESEDO GARAZO, A.: "La hidalguia gallega: caracteristicas esenciales de la nobleza provincial del reino de Galicia durante el Antiguo Régimen", OHM, 10 (2001), pp. 225-245.

${ }^{3}$ Este porcentaje de vecinos hidalgos, que también incluye a los considerados nobles, ha sido tomado de ReY CASTELAO, Ofelia: A Galicia clásica e barroca, Vigo, 1998, p. 243; y el de la población hidalga, de Gasalla Regueiro, Pedro luis y Saavedha Fernandez, Pegerto: "Alumnos, bachilleres y catedráticos en el siglo XVIII", in BARREIRo FERNÁndez, Xosé Ramón (coord.): Historia de la Universidad de Santiago de Compostela. T. I, De los origenes al siglo xIX, Santiago de Compostela, 2000, p. 511

${ }^{4}$ Dato tomado de Saavedra Fernandez, P. y Villares Paz, R.: «Galicia en el Antiguo Régimen: la fortaleza de una sociedad tradicional», in FERNánDEZ, R. (ed.): España en el siglo xVIII. Homenaje a Pierre Vilar, Barcelona, 1985, p. 446. Si aplicamos a esta cantidad el porcentaje del $5 \%$ señalado por P. L. Gasalla Regueiro y P. Saavedra Fernández para la población hidalga gallega en 1752 (op. cit), habría unos $64.965,6$ individuos en el reino de Galicia a los que, a mediados del siglo xVIl, se les respetaban los privilegios inherentes a dicha calidad nobiliaria tras ser reconocidos como hidalgos en el ámbito local. 
Existían, eso sí, algunas diferencias estructurales entre una comarca y otra, e incluso, si aplicamos análisis microhistóricos, sería posible detectar asimetrías intraestamentales que afectan a los individuos identificados como hidalgos en una misma circunscripción, que nos impiden referirnos a dicho sector social privilegiado como si de un grupo homogéneo y hermético se tratase ${ }^{5}$. Al contrario, lo que prima - a la luz de los recientes estudios realizados - es la heterogeneidad estamental, fácilmente comprobable si atendemos a los desiguales niveles de fortuna que se pueden detectar en el seno del grupo, e igualmente si nos fijamos en los no menos diversos orígenes sociológicos y cronológicos de quienes se hallan integrados en dicho sector ${ }^{6}$.

Por norma, se constata una mayor presencia hidalga en las provincias interiores, en torno al $8 \%$ en $\mathrm{Lugo}^{7}$, en contraste con lo que sucede en las provincias de la Galicia occidental, en donde este contingente dificilmente era capaz de superar el listón del $2 \%^{8}$. Pero incluso dentro de este panorama general, era notoria una mayor concentración hidalga en el entorno urbano que en el rural ${ }^{9}, y$

${ }^{5}$ Véase sino el ejemplo representativo de la hidalguia rural de las comarcas de Arzúa y Melide, en Presedo Garazo, A.: Dueños y..., pp. 96 ss. y 343-346.

${ }^{6}$ Cl. Migués Rodriguez, V. M.: As terras..., pp. 123-135 ; Presedo Garazo, A.: Dueños y..., pp. 230 231; y Dominguez CASTRO, L.: "Las tierras vinculares orensanas a finales del Antiguo Régimen; origen y formas de explotación", en Fernandez PRIETo, Lourenzo y Balboa Lofez, Xesús: La sociedad rural en la España contemporánea. Mercado y patrimonio, Sada, 1996, pp. 126-130.

7 Burgo LópEz, Concepción: «Hidalgos, clérigos y artesanos: la sociedad lucense a mediados del siglo XVIII', en Fernádez Cortizo, Camilo, González Lopo, Domingo L. y Martinez Rodriguez, Enrique (eds.): Universitas. Homenaje a Antonio Eiras Roel, Santiago de Compostela, 2002, t. I, p. 368

${ }^{8}$ De hecho, en la Galicia occidental, la hidalguía acostumbraba a representar un $1,10 \%$ en la estructura de los sectores profesionales de la sociedad rural en 1752, tal como ha demostrado DuBERT GARCiA, Isidro: Historia de la familia en Galicia durante la Época Moderna, 1550-1830 (Estructura, Modelos hereditarios y Conflictividad), Sada, 1992, p. 116. Algunos datos correspondientes a ciertas comarcas y jurisdicciones de la antigua provincia de Santiago durante el siglo XVIII pueden servirnos para confirmar más concretamente dicha tendencia:

\begin{tabular}{ccc}
\hline comarca ó jurisdicción & fecha & \% de vecinos hidalgos \\
\hline Montes & 1752 & 0,46 \\
A Ulla & 1752 & 0,79 \\
Morrazo & $1708-1787$ & $1,14-1,20$ \\
Trasdeza & $1708-1717$ & 1,86 \\
\hline
\end{tabular}

Fuente: Fernádez Cortizo, C.: "Púlpitos y escribanías: los origenes de los linajes hidalgos en Tierra de Montes (ss. XVI-XVIII)", en Fernadez Cortizo, C., Gonzallez Lopo, D. L. y Martinez Rodriguez, E. (eds.): Universitas..., p. 237; REY CASTELAO, O.: Aproximación a la historia rural en la comarca de La Ulla (siglos XVII y XVIII), Santiago de Compostela, 1981, p. 153; y Rodriguez FERreIfo, Hilario: "La hidalguía rural del Morrazo en el siglo XVII: Análisis sociológico de un grupo dirigente», en EIRAs RoEL, Antonio et al: La historia social de Galicia en sus fuentes de protocolos, Santiago de Compostela, 1981, p. 219, y La Tierra de Trasdeza, una economía rural antigua. Población y economía en la antigua jurisdicción de Trasdeza en la primera mitad del siglo xVIII, Santiago de Compostela, 1973, p. 83.

9 Asi, por ejemplo, tal como ha señalado Ofelia Rey Castelao, la hidalguía suponía, en 1752, el $15,5 \%$ de los vecinos de la ciudad de Lugo, el $28,6 \%$ en Coruña, y el $22,5 \%$ en Ourense, siendo superados estos porcentajes, incluso, por algunas villas del interioi, tales como Monforte, Verín y Monterrei (Cf. A Galicia..., p. 244). El porcentaje de Lugo experimentó, además, un ligero incremento, si tenemos en cuenta los datos procedentes del padrón de vecinos de 1763, momento en el cual los vecinos hidalgos representaban un $16 \%$ sobre el vecindario de dicha ciudad (Cf. BURGo LóPEZ, C.: «Lugo na Ida de 
además, en este segundo ámbito, había algunas comarcas rurales en las que su presencia, sin alcanzar los elevados porcentajes de villas y ciudades, podia llegar a superar los valores porcentuales aplicables a la provincia en la cual se asientan ${ }^{10}$.

Estos individuos habían sido borrados de las listas de pecheros debido a su calidad de hidalgos, y, por tanto, estaban exentos de contribuir al servicio real. Sin embargo, cuentan con origenes sociológicos enormemente dispares ${ }^{11}$. Una parte de ellos, que hemos de considerar minoritaria, todavía pueden entroncar por línea directa de varonía con sus antepasados remotos de origen hidalgo que habian fundado los primeros mayorazgos de la casa poco antes de mediados del siglo XVI, y que habian ampliado el patrimonio de la misma a costa del mercado de la tierra, básicamente entre 1580 y $1650^{12}$. Bastantes más procedian de ramas familiares, también troncales, que habian arrancado de segundones de estas antiguas casas hidalgas ${ }^{13}$, o de individuos que habian estado al servicio de ellas, generalmente desempeñando el cargo de escuderos ${ }^{14}$, que también aparecen plenamente asentadas a mediados del Quinientos. Pero la gran mayoría había adquirido más recientemente (entre 1650 y 1750 ) el estatus de hidalguía vía política matrimonial y

Moderna", in Arias ViLAS, Felipe et al: Historia de Lugo, A Coruña, 2001, p. 134). Otras ciudades y villas presentaban, al contrario, unos porcentajes bastante más bajos de vecinos hidalgos, como por ejemplo Betanzos con su $6,10 \%$, que, pese a ello, superaba con creces al porcentaje medio de hidalgos en los núcleos rurales occidentales (Ct. VAQUERO LASTRES, Berta María: «La hidalguía en Betanzos en el siglo XVIII: la familia y la vivienda", Anuario Brigantino, 9 (1986), p. 53); del mismo modo que sucedía en la villa de Rianxo, con su $2,93 \%$ de vecinos de condición hidalga (dato calculado a partir de Comoxo, Xosé y SAntos, Xesús: A heráldica nas terras de Rianxo: brasóns e liñaxes, A Coruña, 1997, pp. 53-54).

${ }_{10}$ Es lo que sucede, por ejemplo, con el elevado $15 \%$ de vecinos hidalgos asentados en el Concejo de Burón en 1752, que superan con creces a la media provincial del $8 \%$ de Lugo, aunque no al $15,5-16 \%$ de la capital (Cf. SAAVEDRA FERnández, P.: Economia rurai antigua en la montaña lucense. El Concejo de Burón, Santiago de Compostela, 1979, p. 78). No menos representativo resulta, en la provincia de Ourense, el elevado $19,51 \%$ de vecinos hidalgos que residen en el Coto de Cudeiro, sito en la comarca vitivinícola del Ribeiro do Miño, frente al $22,50 \%$ de la capital (dato calculado a partir de Archivo Histórico Provincial de Ourense [AHPOu], Catastro de Ensenada [CE], Libros de Personales de Legos, lib. 2541,

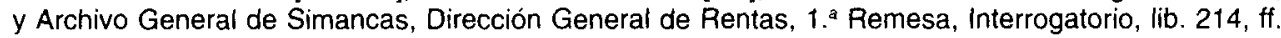
370r. sigs.).

${ }^{11}$ Hemos tenido ocasión de aproximarnos a esta cuestión con algo más de detalle en nuestro trabajo reciente titulado "Estudiantes de condición nobiliaria en la Universidad de Santiago de Compostela (siglos xVII y XVIII): Aproximación a su perfil sociológico», Hispania, 215 (2003), pp. 907-968.

12 Un ejemplo que se ajusta a esta casuística es el de la Casa de Torés, del linaje de Ribadeneira, sita en la franja oriental de la provincia de Lugo, a tenor de la documentación consultada en el Archivo Ducal de Medinaceli, Torés, legs. 1, 5, 6 y 11.

${ }_{13}$ La Casa de Noceda, en As Nogais (Lugo), entra dentro de este grupo, puesto que sus orígenes históricos, que se remontan hasta finales del siglo xv, se hallan, precisamente, en una rama troncal de la Casa de Torés citada en la nota precedente. AHPOu, Casas Particulares (CP), Casa do Castro, Noceda, cajas 5 y 6.

${ }_{14}$ Tal como sucede con la Casa de Lagariños, en Coles (Ourense), estudiada por el Prof. Ramón Villares, cuyo origen se halla en Lopo Conde, quien había servido al conde de Ribadavia en calidad de escudero (Cf. VILlARES PAZ, R.: La propiedad de la tierra en Galicia, 1500-1936, Madrid, 1982, p. 77). Otro ejemplo igualmente significativo es el de la Casa de Mirapeixe, en Rábade (Lugo), cuya mejora vincular otorga Alonso Ares Sanxurxo da Barreira en 1565, quien habia ejercido de merino y justicia en la villa de Outeiro de Rei, por tanto, al servicio del conde de Vilalba. Archivo de la Casa de Mirapeixe (en Rábade) (ACM), Mirapeixe, caja 1. 
unas estrategias de reproducción social muy calculadas ${ }^{15}$, y sus primeros antepasados que se habian decantado por ennoblecer su sangre eran gentes procedentes del ámbito del derecho ${ }^{16}$, de la milicia ${ }^{17}$, del clero ${ }^{18}$, del comercio ${ }^{19}$, e incluso también - merced a la enorme polarización que experimenta la sociedad gallega en esta etapa histórica- de los sectores más aventajados del escaso campesinado acomodado, con suficiente capacidad económica como para acumular excedentes agrarios ${ }^{20}$.

Junto con estos desiguales ritmos de acceso a la hidalguía y los heterogéneos orígenes sociales por parte de quienes la integran, también se hallan de telón de fondo a la hora de explicar la gran diversidad compositiva de este mayoritario sector nobiliario a mediados del siglo XVIII, las distintas oportunidades de acumular un patrimonio extenso - a la vez material e inmaterial--, o por el contrario, de más reducidas dimensiones ${ }^{21}$. Así que a estas alturas tan avanzadas de la Época Moderna gallega, resulta prácticamente insalvable el abismo económico, e incluso intraestamental, que separa al reducido grupo de casas hidalgas que habian sido capaces de acumular unos ingresos superiores a $1.000 \mathrm{His}$. anuales ${ }^{22}$, básicamente

15 Según un muestreo compuesto por una veintena de casas hidalgas dispersas por buena parte de la Galicia interior, el momento de mayor actividad fundacional se encuentra, principalmente, en 16501750 (Cf. Presedo Garazo, A.: Dueños y..., pp. 195-197); coincidiendo, por tanto, con los resultados obtenidos por María Teresa Pérez Picazo para el reino de Murcia (Cf. El mayorazgo en la historia económica de la región murciana. Expansión, crisis y abolición (s. xvil-xix), Madrid, 1990, p. 53).

16 Por ejemplo, la Casa de San Fiz, en Chantada (Lugo), que tiene su origen en el escribano Esteban Tenreiro, tal como nos recuerda VILLARES PAZ, R.: La propiedad..., p. 77; o algunas de las casas hidalgas de la Tierra de Montes (entre ellas, la del linaje de los Ogando), estudiadas recientemente por FERNADEZ CORTIzo, C.: «Púlpitos y... ", pp. 239-245.

17 Sirvan de ejemplo algunas de las casas hidalgas que entroncan con la Casa-Nova de Golán, en Melide (A Coruña), a partir de mediados del siglo XVII, en el Archivo de la Casa da Fraga (en Friol) (ACF), Libro becerro redactado por el hidalgo don Juan Francisco Valeriano Varela y Aguiar.

18 LeIRós de la Peña, P.: La casa..., p. 10.

19 Ferro Couselo, Xesús: "Gente llana con ventura. Los Boanes", Boletín Avriense [en adelante $B A v$ II (1972), p. 8. También se incluye alguna información -aunque resulta francamente minoritariasobre antepasados de casas hidalgas gallegas que se dedicaron a actividades comerciales, entre los expedientes de limpieza de sangre de los colegiales que obtuvieron una beca en el Colegio Mayor de Fonseca de la Universidad de Santiago de Compostela entre 1580 y 1800 (Archivo Histórico Universitario de Santiago [AHUS], Fondo de la Universidad, Sección Histórica, Pruebas de limpieza de sangre, legs. 202209 y 365-373). Véase un reciente análisis en este mismo sentido en Presedo Garazo, A.: “Estudiantes...". Sin lugar a dudas, la reflexión más acertada en relación con este aspecto de la sociología de los origenes de la hidalguia gallega, la debemos a SaAvedra FERnandez, P.: Economia, Política y Sociedad en Galicia: la provincia de Mondoñedo, 1480-1830, Madrid, 1985, pp. 567-571

20 Presedo Garazo, A.: «A pequena fidalguía rural e a parceria de gando: a casa da Fraga de San Xiao de Carballo -Friol- (\$680-1800)", Cuadernos de Estudios Gallegos [en adelante CEG], XLIII (1997), pp. 53 ss.

21 En relación con las diversas estrategias económicas seguidas por la hidalguia gallega a la hora de consolidar sus patrimonios, vid. los trabajos íundamentales de VILLARES PAZ, R.: La propiedad..., pp. 80 Ss.; y SaAvedra Fernández, P.: Economía..., pp. 436 ss.

22 Como atestiguan, entre otros, al marquesado de Montaos, con 942 Hls./año en 1744 (AHUS, Fondos privados, Marquesado de Montaos, caja 15, n. ${ }^{\circ}$ 19), la Casa de Noceda, con 1.025,67 Hls./año en 1777 (AHPOu, CP, Casa do Castro, Noceda, caja 7, n. ${ }^{\circ} 20$ ), el marquesado de Mos, con $1.548,12$ HIs./año en 1787 (AHPOu, CP, Casa do Castro, Noceda, caja 2), o el marquesado de San Martiño de Hombreiro (Cf. Migués Rodriguez, V. M.: A fidalguía..., p. 114). 
en cereales y vino, merced a una exitosa política secular de entronques familiares y a una formidable capacidad para actuar sobre el mercado de la tierra, que asimismo debemos considerar perfectamente integradas en la elite de rentistas laicos ya urbanizada del reino ${ }^{23}$, de aquella otra mayoritaria hidalguía rural modesta cuyos patrimonios agropecuarios resultaban, en ocasiones, de menores dimensiones que los del campesinado acomodado que residía en las proximidades de su casagrande, y que, debido a esta circunstancia, se habian visto obligados a trabajar directamente sus explotaciones agricolas ${ }^{24}$.

Ahora bien, todos ellos gozaban de gran reconocimiento, y sobre todo prestigio, en aquellas poblaciones próximas al lugar de emplazamiento del solar originario de su casa ${ }^{25}$ — verdadera piedra angular de su capital simbólico-, sobre el cual había sido construida, y en ocasiones reedificada, su característica residencia nobiliaria, que en Galicia responde al término de $p a z o^{26}$, en la que acostumbraban a residir - aunque en el caso de las familias más acomodadas, tan sólo en contadas ocasiones a lo largo del año ${ }^{27}$ _. Precisamente, a mediados del siglo XVIII, estos majestuosos edificios residenciales, que todavía hoy en día pueblan la campiña y los valles gallegos ${ }^{28}$, contaban con una enorme carga simbólica de vital importancia para las familias hidalgas que los poseían, puesto que no sólo eran el centro económico en torno al cual giraban multitud de intereses -laberínticos en ocasiones-, sino que representaban en sí mismos el éxito de estas familias que, generación tras generación, habían residido dentro de sus paredes gestionando un patrimonio amortizado en sucesivos vínculos. No en vano, sus gruesas murallas y paredes eran una metáfora perfecta de la solidez del modelo de familia troncal, propio de la hidalguia gallega moderna, basada en un sistema de reproducción social centrípeta que tenía en la casa su verdadero epicentro organizador.

23 Puesto que se trata de rentistas que incluso superan ampliamente el listón del los $200 \mathrm{Hls}$./año con que el Prof. Ramón Villares identificó a los rentistas excepcionales en la Galicia del Antiguo Régimen (Cf. La propiedad..., p. 50).

${ }_{24}$ Tal como venía sucediendo en el Concejo de Burón, en las comarcas de A Ulla y O Morrazo, y en buena parte de la provincia de Ourense. Cf. SaAvedra Fernández, P.: Economia..., pp. 78 ss.; Rey CASTELAO, O.: Aproximación a la historia rural.., p. 159; RODRIGUEZ FERREIRO, Hilario: “La hidalguía...", p. 233; y Dominguez CAStRo, L.: «Las tierras...", p. 129. Hemos de tener en cuenta, además, que esta proliferación de dicha hidalguía que podemos denominar humilde, no era exclusiva del ámbito rural, puesto que también acostumbraba a abundar en el entorno urbano, como demostró en su día, para el caso de la ciudad de Santiago de Compostela, el Prof. EIRAS ROEL, A.: «Las élites urbanas de una ciudad tradicional: Santiago de Compostela a mediados del siglo XVIII", in VV.AA.: La Documentación Notarial y la Historia, Santiago de Compostela, 1984, t. I, pp. 119-122. En otra capital de provincia de la Galicia occidental, como de hecho lu era Betanzos, la elite hidalga tan sólo llegaba a representar un $33 \%$ de dicho sector nobiliario (Cf. VAQUERO LASTRES, B. M.a: "La hidalguia...", p. 55).

25 SaAvedra Fernández, P.: «Formación...", pp. 139-146.

26 VILA Jato, Maria Dolores: “El pazo en Galicia», in Ramallo Asensio, Germán (coord.): Arquitectura señorial en el Norte de España, Oviedo, 1993, pp. 27-43.

27 Presedo Garazo, A.: «O luxo na fidalguía galega a través do exemplo da Casa-Torre de Raíndo, 1798-1800", in Alonso GiRgado, Luis (coord.): Homenaxe ó Profesor Manuel Quintáns, Santiago de Compostela, 1999, pp. 186-188.

${ }^{28}$ Cf. Garcia IGlesias, Xosé Manuel y COAG: Pazos de Galicia, 2 vols., Santiago de Compostela, 1989; y Lobato, Xurxo (coord.): La Galicia de los pazos, A Coruña, 2001. 


\section{ESTRUCTURA DE LOS HOGARES HIDALGOS GALLEGOS A MEDIADOS DEL SIGLO XVIII}

Esta dinámica centrípeta se habia consolidado bastante tiempo atrás, justo cuando, en los dos primeros cuartos del siglo XVI, los antiguos sectores laicos más aventajados de la sociedad bajomedieval gallega, entre ellos, algunos hidalgos y, sobre todo, oficiales jurisdiccionales que habian estado al servicio de las poderosas casas nobiliarias, habian conseguido adaptarse a los nuevos tiempos basando su poder en un patrimonio que, merced a una interpretación interesada de las Leyes de Toro aprobadas en 1505, podía ser integrado en mejoras vinculares sin necesidad de disponer para ello de licencia regia, y adoptando, por emulación, un modelo de reproducción social basado en el mayorazgo, ya puesto en funcionamiento, desde mediados del siglo XV en adelante, por algunas de las casas nobles a las que ellos mismos habian venido siviendo hasta entones ${ }^{29}$.

La lógica por la que se rigen los grupos sociales inmersos en procesos de ascenso social en las sociedades europeas de Antiguo Régimen, de imitar los hábitos y comportamientos de aquellos sectores de la sociedad dominantes que ya gozan de cierto reconocimiento social y de un estatus aventajado ${ }^{30}$, fue determinante para que este modelo reproductivo, tempranamente adaptado a las nuevas necesidades que se le plantean al estamento noble gallego con la llegada del siglo XVI $\multimap$ lo que lo mismo, tras el óbito de Isabel 1 - se pudiese difundir, con una facilidad que no deja de ser sorprendente ${ }^{31}$, entre aquellos sectores de la sociedad tardofeudal que consiguieron acceder a la calidad de hidalgos entre 1550 y 1750.

La casa, junto con los principales elementos simbólicos que la representan -básicamente, un apellido compuesto y unas armerías cada vez más complejas-, el grupo de individuos que la integran --sometidos a una lógica contraria al individualismo y tendente a favorecer un comportamiento univoco-, y el patrimonio vincular que permite su decente sustentación, habian marcado, pues, desde bien pronto, los pasos a seguir por todos los miembros de las familias hidalgas gallegas que cohabitaban bajo un mismo techo que sus parientes que de-

29 Fernández Suárez, Gonzalo Francisco, Framiñan Santas, Ana María y Presedo Garazo, A.: "Galicia en 1480: La readaptación del estamento nobiliario", in VV.AA.: Enfrontaments civils: Postguerres $i$ reconstruccions, Lleida, 2002, pp. 44-47.

30 Véase sino para el caso portugués, el ejemplo de las prácticas de reproducción social seguidas por las familias integradas en las redes de clientela de la Casa de Bragança entre 1560 y 1640 , en SOARES DA Cunha, Mafalda: A Casa de Bragança, 1560-1640. Práticas senhoriais e redes clientelares, Lisboa, 2000 , pp. 468 ss. Véase también, en relación con el ámbito inglés, STONE, Lawrence \& FaWTIER STONE, Jeanne C.: An Open Elite? England, 1540-1880, Oxford \& New York, 1986.

${ }^{31}$ Esta afirmación se debe, en buena medida, al hecho de que a partir del siglo XVII ( $y$, sobre todo, en la segunda mitad de dicha cerituria), este modelo de reproducción social basado en la casa y en las mejoras vinculares va a ser adoptado por la mayoria del campesinado lugués, tal como ha podido demostrar extensamente Hortensio Sobrado, para quien "Este incremento de protagonismo de la mejora en tierras lucenses [es] fruto de una imitación cultural de la hidalguia, o por puras necesidades económicas". Cf. Sobrado Correa, Hortensio: Las Tierras de Lugo en la Edad Moderna. Economia campesina, familia y herencia, 1550-1860, A Coruña, 2001, pp. 400 ss. 
tentaban la jefatura ${ }^{32}$. $Y$ todos ellos, incluidos estos últimos, que acostumbran a aparecer reflejados en la documentación bajo la fórmula de «dueños" 0 "señores" de casa, se identificaban con un nexo común, ya no excesivamente remoto - como sucedía con los nobles gallegos que habían conseguido un título-, pero con cierta antigüedad, al cual se sometían y aferraban para proteger su condición privilegiada, basada en el hecho de haber sido reconocidos como hidalgos.

Consecuentemente, la casa operaba como un referente simbólico teórico para quienes la integraban, a la vez que se identificaba con un soporte material, generalmente compuesto por los bienes incorporados a los vínculos que habian fundado sus antepasados, y que se pretendía transmitir por línea sucesoria agnaticia. La aceptación de este presupuesto por parte de un individuo nacido en el seno de una casa hidalga gallega en el transcurso del siglo xVIII, implicaba, antes de nada, reconocer que formaba parte de una cadena familiar cuyos eslabones habían sido forjados bajo el signo de la renuncia personal en pro de un proyecto en común, que la propia casa había ido diseñando una generación tras otra, desde poco antes del momento en que un antepasado biológico, selectivamente identificado por la memoria familiar ${ }^{33}$, había decidido iniciar con éxito la actividad fundacional de la casa y su particular acceso a los privilegios inherentes a la hidalguía. El testimonio del hidalgo orensano don Francisco Gómez de Puga y Arauxo, procedente de una obra autógrafa suya en la que el susodicho pretende describir sus orígenes genealógicos a comienzos de esta centuria, refleja perfectamente la idea que pretendemos transmitir, cuando, con orgullo, admite que:

"Siguiendo lo mas verídico que a mi juizio, y de otros, en el espacio de algunos años pude acaudalar: resuelvo dirigir mi pluma al paso de su posibilidad y fuerzas, a mis padres y mas ascendientes que mi cuidado pudo alcanzar: para que los descendientes o venideros den repetidas gracias al criador: imitando en lo posible los memorables y bien dispuestos vestigios de nuestros antecesores; y mediante la divina gracia y misericordia seguirles en esta cortisima vida para verles con infinito gozo en la eterna» ${ }^{34}$.

\footnotetext{
${ }^{32}$ En relación con la lógica de casa imperante en las casas aristocráticas europeas, resultan muy acertadas, por su coincidencia con algunos de los principales aspectos del modelo gallego, las diversas aportaciones que debemos en este mismo sentido al Prof. Nuno G. Monteiro para el caso portugués: "Casa e Linhagem: o Vocabulario Aristocrático em Portugal nos Séculos XVII e XVIII", Penélope. Revista de História e Ciências Sociais, 12 (Lisboa, 1993), pp. 43-63; "Casamento, celibato e reprodução social: a aristocrácia portuguesa nos séculos XVII e XVIII", Análise Social, 123-124 (Lisboa, 1993), pp. 921-950; "Casa, reprodução social e celibato: a aristocrácia portuguesa nos séculos XVII e XVIII", Hispania, 185, (1993), pp.907-936; O crepúsculos dos Grandes. A casa e o patromónio da aristocrácia em Portugal (1750-1832), Lisboa, 1998, pp. 57 ss.; y “Aristocratic Succession in Portugal (From the Sixteenth to the Nineteenth Centuries", in PINA-CABral, João (de) \& PEdroso Lima, Antónia (eds.): Elites. Choice, Leadership and Succession, Oxford, 2000, pp. 133-148.

${ }^{33}$ Cf. CAmões GouveiA, António: «A linhagem ou o tempo da memória. D. Francisco Manuel de Melo e o nobre seiscentista", Ler História, 18 (Lisboa, 1990), p. 3.

${ }^{34}$ Francisco Gómez de Puga y Arauxo. Historia particular de cuatro ramos de que un cristiano tronco se compone, y con humilde fin se endereza a la alabanza y gloria del Criador santisimo del universo, ca. 1704-1705, ms. Cit. por FARIÑA CouTo, Luciano: «Notas sobre heráldica y genealogia de algunos linajes del Ribeiro de Avia deducidas de un manuscrito de comienzos del siglo XVIII", BAvr, XXIII, 1993, p. 257.
} 
Los datos procedentes de los Libros de Personales de Legos del Catastro de Ensenada de algunas comarcas del interior gallego ${ }^{35}$, en las cuales se constata una mayor presencia hidalga ${ }^{36}$, no hacen sino confirmar el triunfo de esta dinámica en la que es manifiesta la enorme dependencia del individuo hacia la casa en que ha nacido y ha sido educado conforme a un rol específico, y al cual debería someterse a lo largo de su vida.

Por norma, estos hogares hidalgos eran más extensos que los del resto de sus vecinos que aparecen asentados en los libros catastrales, al margen de que fuesen eclesiásticos o laicos ${ }^{37}$ : de media, en la comarca de Lugo alcanzaban los 7 individuos $^{38}$, en la de Ourense 6,65, y en las de Arzúa y Melide, conjuntamente, 6,58, superando, en casi todos los casos las respectivas medias comarcales ${ }^{39}$. Generalmente, los hogares hidalgos de los núcleos urbanos contaban con un número de efectivos ligeramente mayor: sólo por citar algún ejemplo, podemos referirnos de más a menos, a los 8,10 individuos por hogar -incluyendo a las gentes del servicio- de Pontevedra, los 7,48 de Santiago de Compostela, los 7,03 de Lugo, los 6,94 de Ourense, los 6,44 de Monforte y los 6,20 de Betanzos ${ }^{40}$. Del mismo modo, tampoco existía en todos estos hogares - rurales o urbanos - un comportamiento unívoco en cuanto al número de sus miembros se refiere. En el interior de la actual provincia de A Coruña, en las comarcas de Arzúa y Melide (Gráfico 1) —en donde, recordemos, la media de efectivos por hogar hidalgo se sitúa en 6,58-, la mayor parte de los individuos de calidad hidalga aquí residentes, junto con las gentes del servicio que les acompañan, acostumbraban a pertenecer a hogares de entre 2 y 7 miembros, e incluso de 11; si bien es cierto que los de 5 ocupaban el pri-

35 Exactamente, de las dos comarcas de Arzúa y Melide en el interior de la actual provincia de A Coruña (ayuntamientos de Arzúa, Boimorto, Curtis, Melide, (O) Pino, Santiso, Sobrado, Toques, Touro y Vilasantar), y de la comarca de Ourense, que se halla en el extremo nororiental de la de Ourense (ayuntamientos de Amoeiro, Barbadás, Coles, Esgos, Nogueira de Ramuín, Ourense, (O) Pereiro de Aguiar, (A) Peroxa, San Cibrao das Viñas, Taboadela, Toén y Vilamarín). Las bases de datos que apoyan nuestras afirmaciones han sido elaboradas a partir de los Libros de Personales de Legos del Catastro de Ensenada correspondientes a los ayuntamientos comprendidos por estas tres comarcas. Para Arzúa y Melide, Archivo Histórico del Reino de Galicia, Catastro de Ensenada (CE), libs. 14, 39, 92, 125, 167, $196,228,233,357,378,416,433,466,489,523,602,639,681,730,735,740,798,810,858,949$, $1027,1203,1226,1268,1327,1406,1496,1541,1580,1662,1705,1763,1786,1792,1972,2046$, $2137,2175,2184,2271,2322,2327,2451,2511,2571,2758,2794,2912,2938,3041$ y 3073. Y para Ourense, AHPOu, CE, libs. 567, 657, 1037, 1038, 1046, 1050, 1301, 1305, 1308, 1311, 1313, 1316, $1318,1320,1324,1326,1330,1802,1806,1810,1814,1817,1938,1941,1944,1946,2479,2484$, $2487,2489,2490,2496,2500,2503,2506,2527,2530,2534,2538,2541,2545,2549,2551,2554$, $2557,2560,2568,2573,2579,2586,2590,2597,2601,2604,2607,2708,2710,2713,2715,2717$, $2723,2726,2729,2732,2736,2739,2746,2749,2753,2757,2766,2772,2774,3097,3101,3106$, $3114,3122,3127,3166,3170,3173,3177,3188,3199,3215,3219,3222,3226,3230,3233,3237$, $3240,3244,3247,3456,3460,3463,3466,3469,3472,3689,3692$ у 3705.

36 Rey Castelao, O.: La Galicia..., p. 243.

37 Véase la Tabla 1.b del Apéndice estadístico.

38 Sobrado CoRrea, $\mathrm{H}$.: Las Tierras..., pp. 85-86.

39 Así, por ejemplo, en las Tierras de Lugo, si el número medio de miembros por hogar que predominaba en el entorno rural era de 5,26, y el de los hogares hidalgos era de 7,01, de la diferencia entre ambos resultaba una ventaja de 1,75 miembros a favor de estos segundos. lbid., pp. 84-86.

40 Burgo López, C.: «Hidalgos...", p. 368; y Dubert Garcia, I.: Historia..., p. 159. 


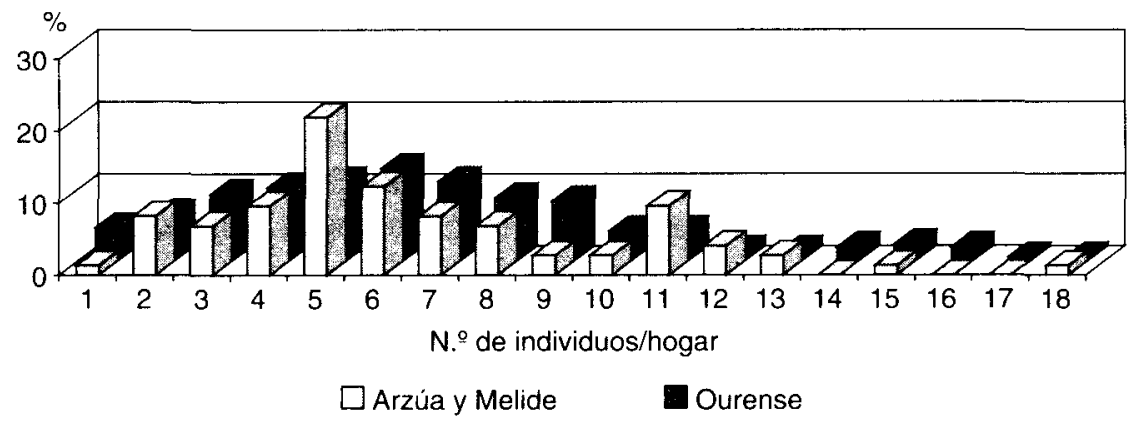

Gráfico 1. Comparación entre los tamaños de los hogares hidalgos de las comarcas de Arzúa y Melide con la de Ourense en 1752.

mer puesto $(21,91 \%)$, los de 6 el segundo $(12,32 \%)$, y tanto los de 4 como los de 11 compartían el tercero $(9,58 \%)$. En la comarca de Ourense -que ofrece una media de 6,65 individuos por cada hogar hidalgo- nos encontramos nuevamente con una pauta conductual similar: los tamaños de hogares que más se repiten se sitúan entre 3 y 9 miembros, correspondiéndole a los de 6 el primer puesto $(12,84 \%)$, a los de 5 y 7 el segundo (11\%), y a los de 3 el tercero $(9,17 \%)$.

Otro elemento que llama la atención de estos hogares extensos radica en el hecho de que las gentes del servicio tan sólo representan entre el 26,27 y el $39,91 \%$ de los efectivos contabilizados ${ }^{41}$, por lo que entre un 60 y un $73,72 \%$ de los individuos integrados en los mismos se hallan unidos por estrechos lazos familiares que no acostumbran a superar el tercer grado en la línea de parentesco, $y$, por tanto, de ellos va a depender la posibilidad de que la casa llegue a perpetuarse en el futuro como célula reproductora.

Se aprecia, igualmente, un equilibrio entre los dos géneros, si bien es cierto que los varones consiguen superar ligeramente - tan sólo en un punto y medio- a las mujeres; aunque si atendemos al volumen total de individuos que residen en estos hogares, sumando a la vez los miembros de las familias hidalgas y las gentes del servicio, ambos porcentajes tienden a mostrar valores idénticos ${ }^{42}$. Esto es, junto a los jefes, residen por igual parientes del género masculino y del género femenino.

41 No obstante, hemos de advertir a los posibles lectores que no hemos pretendido valorar, en la presente reflexión, ei importante papel que desempeñaron las gentes del servicio en las casas hidalgas gallegas en esta etapa histórica, puesto que se trata de una cuestión que requeriría por sí misma de una reflexión monográfica. Puede consultarse una aproximación a dicha temática, con una descripción detallada de las principales características de este sector poblacional integrado en los hogares hidalgos gallegos, en Presedo Garazo, A.: Dueños..., pp. 512-521. Tan sólo nos interesa retener en esta ocasión, en relación con el tamaño medio de los hogares hidalgos a mediados del siglo XVIII, que el número medio de criados por hogar acostumbraba a situarse entre 1,75 y 2,65 miembros: 1,74 en la comarca de Ourense, 2,5 en la ciudad de Lugo (Cf. BuRgo LOPEZ, C.: "Hidalgos...", p. 368), 2,6 en la ciudad de Betanzos y sus alrededores (Cf. VAQUERO LASTRES, B. M.a: “La hidalguía...", p. 58), y 2,63 conjuntamente en las comarcas de Arzúa y Melide.

42 Véase la Tabla 1.b del Apéndice estadístico. 
El análisis de las estructuras familiares denota el peso destacado -aunque no hegemónico- de los hogares complejos entre esta hidalguía ampliamente ruralizada $^{43}$. Sin embargo, conviene matizar algunos aspectos. Lo primero que llama la atención es que el modelo de familia nuclear resulta predominante tanto en el interior de la actual provincia de A Coruña como en el extremo noroccidental de Ourense $^{44}$, lo cual no resulta extraño si tenemos en cuenta que se trata de la estructura imperante en las familias gallegas del momento ${ }^{45}$. En ambas áreas, la modalidad de "pareja conyugal sin prole" resulta minoritaria, en beneficio de la tipologia "pareja conyugal con prole" - mayoritaria en Ourense con un $63,35 \%$ sobre la totalidad de los hogares hidalgos nucleares-, y de la de "viudo/a con prole" - principal modalidad nuclear en Arzúa y Melide, al suponer un $50 \%$ de este conjunto-. No menos relevantes hemos de considerar a los hogares hidalgos con estructura solitaria, en la medida en que, en estas comarcas siempre superan a los múltiples. E incluso dentro de éstos, el predominio de los/as solteros/as frente a los/as viudos/as nos está indicando que un nada desdeñable $58,33 \%$ de los hogares solitarios de Arzúa y Melide, además de un $77,77 \%$ de los de Ourense, estaban regentados por hidalgos célibes que habían sido capaces de prescindir de la casa. O lo que es lo mismo, también estamos asistiendo a la aparición de las primeras emancipaciones de familiares que pretenden situarse al margen de dicha dinámica pese a su origen hidalgo, y que finalmente, ya introducidos en el siglo XIX, harán tambalear dicho modelo reproductivo, sobre todo a partir de mediados de dicha centuria ${ }^{46}$.

Las familias hidalgas que se organizan a partir de una estructura familiar extensa en estas tres comarcas rurales de la Galicia interior ocupan el segundo puesto, justo después de las que cuentan con una estructura nuclear. Incluso si les añadimos los hogares que presentan una estructura múltiple, llegarian a superar el tercio del total analizado: un $34,23 \%$ en Arzúa y Melide, y un $31,01 \%$ Ourense. Se trata, a no dudarlo, de una de las pruebas más evidentes de la troncalidad característica de los hogares hidalgos gallegos, estrechamente condicionada por la

43 Véase la Tabla 2 del Apéndice estadístico.

44 Asi como en los hogares hidalgos de la ciudad de Betanzos y sus alrededores, donde el porcentaje de hogares hidalgos con estructura familiar nuclear representa el $68,80 \%$ sobre el total de familias hidalgas. Cf. VAquero LASTRES, B. M. a: "La hidalguia...", p. 55.

${ }_{45} \mathrm{Tal}$ como han puesto de manifiesto reiteradamente los modernistas gallegos que se han aproximado al estudio de la familia en las dos últimas décadas. Cf. principalmente las conclusiones de FERNADEZ CORTIZO, C.: “Estrategias familiares y pequeña explotación campesina en la Galicia del siglo XVIII", in SaAVedRa Fernández, P. y VILLARES PAz, R. (eds.): Señores y campesinos en la península ibérica, siglos XVIII-XX, Barcelona, 1991, t. 2, pp. 330-332; y DUBERT GAfCiA, 1.: Historia de.., pp. 89-90. No obstante, nos hacemos partícipes de la reciente reflexión de Hortensio Sobrado en relación con la alta presencia de la tipología nuclear entre los hogares campesinos lucenses a la altura de $1753(48,6 \%)$, que creemos puede servir para explicar la alta representatividad de dicha estructura familiar entre los hogares hidalgos de la Galicia interior: "El análisis de la estructura familiar lucense a través del empleo de la tipologia de Laslett, puede conducir a fomentar una imagen un tanto artificial de las estructuras complejas, reduciendo su importancia cuantitativa respecto a las nucleares" (Cf. SOBrado CORREA, H.: Las Tierras..., p. 89).

${ }^{4}$ Cf. Presedo Garazo, A.: Dueños y..., pp. 319-320. 
adopción de un modelo sucesorio no igualitario que facilita que un individuo concreto, generalmente el pater familias ${ }^{47}$, goce de gran poder dentro del marco de convivencia familiar, en el cual, él va a desempeñar la jefatura de la casa hasta que se formalice, contractual y operativamente, el relevo generacional ${ }^{48}$. Una prueba lo suficientemente expresiva de ello la tenemos en el hecho de que incluso un $24,65 \%$ de los hogares hidalgos de Arzúa y Melide -el principal contingente de los mismos-, aún siendo nucleares, se hallan bajo la jefatura de un/a viudo/a, y lo mismo podemos ver reflejado en Ourense, donde el $16,20 \%$ que supone dicha tipología ocupa el segundo puesto sobre el total, justo después de la modalidad nuclear de "pareja conyugal con prole".

Si atendemos a la edad y al estado civil de los individuos que componen estos hogares $^{49}$, la primacía de la soltería es un hecho incuestionable, tal como se desprende del elevado $67,39 \%$ de los varones y del $68 \%$ de las mujeres pertenecientes a las familias hidalgas de Arzúa y Melide, o del $69,20 \%$ de los varones y del $66,11 \%$ de las mujeres de la hidalguía de Ourense. El porcentaje de individuos que llegan a abandonar el hogar, bien para integrarse en otro distinto, o bien -en menor medida - para fundar otro nuevo, se sitúa, así en un reducido $32,65 \%$ de los varones y un $32 \%$ de las mujeres de los hogares hidalgos arzuanos y melidenses, y en un $30,79 \%$ de los varones y un $33,88 \%$ de las mujeres de los hogares hidalgos orensanos. Es decir, dos tercios de los parientes que residen al amparo del jefe de casa, asi sean hombres o mujeres, viven sometidos a su autoridad en estado de soltería; y únicamente un tercio de los mismos puede plantearse fundar un nuevo hogar o incorporarse a otro, pero después de haber cumplido los 25 años, puesto que son escasos los ejemplos de vástagos/as desposados/as antes de dicho tramo de edad ${ }^{50}$.

47 GaCro, Enrique: «El marco jurídico de la familia en Castilla. Edad Moderna", Historia, Instituciones, Documentos, 11 (1984), pp. 37-66; CHACÓN JIMÉNEZ, Francisco: “Hacia una nueva definición de la estructura social en la España del Antiguo Régimen a través de las familias y las relaciones de parentesco", Historia Social, 21 (1995), pp. 75-104; y RodRiguez SANCHEz, Ángel: "El poder de la familia: la patria potestad en el Antiguo Régimen", Chrónica Nova, 18 (1990), pp. 365 ss.

${ }^{48}$ Cf. Presedo Garazo, A.: Dueños..., pp. 268-275 y 309 ss.

49 Véase la Tabla 3 del Apéndice estadístico.

50 Otros datos referidos a la edad media al primer matrimonio entre las familias nobles de contextos europeos diferentes al gallego, también parecen confirmar dicha tendencia al matrimonio tardío durante el siglo XVIII. Por no extendernos demasiado, y citar tan sólo algunos casos significativos y bien conocidos, pudemos referirnos, en primer lugar, a la edad de los varones al primer matrimonio en el ámbito castellano, para ser más exactos entre la alta nobleza a comienzos de dicha centuria, que Janine Fayard ha situado entre los 30 y los 49 años (Cf. Los miembros del Consejo de Castilla (1621-1746), Madrid, 1982, p. 268). En segundo lugar, en Portugal, según nos recuerda Nuno G. Monteiro, la edad de las mujeres procedentes de las casas de los Grandes al primer matrimonio se va a situar en el tramo 20-29 años a partir de 1750 (Cf. “Casamento...", p. 929). En tercer lugar, en Francia ya está documentada esta edad tardía al primer matrimonio entre la "nobleza pobre" asi como entre la grandeza desde fines del siglo XVI y durante todo el XVII. Tomando como ejemplo el modelo regional bretón, en el período 1701-1769, los nobles varones bretones acceden a su primer matrimonio con 30,8 años y las mujeres con 28,2 . Cf. HuDEMANN-SiMON, C.: "Une noblesse en déclin a la fin de l'Ancien Régime. Le role des circonstances et les effets des comportements dans l'éche du second ordre luxemburgeosis", Histoire, Economie et Societé, Paris, 1986, p. 91; LABAUT, J.-P.: Les ducs et pairs de France au XVII siècle, Paris, 1972, p. 136 ; MEYER, J.: “Noblesse des bocages : essai de typologie d'una noblesse provinciale», in KöPECZI, B. \& BáLAZs, E.H. 
Prácticamente la totalidad de la prole permanece soltera mientras reside bajo el amparo de la autoridad paterna ${ }^{51}$. En Arzúa y Melide, se hallan en esta tesitura el $100 \%$ de los hijos y el $98,14 \%$ de las hijas, y en Ourense, el $97,34 \%$ de los hijos $y$ el $95,74 \%$ de las hijas. Por lo que el porcentaje de hijos e hijas casados/as para casa no sólo resulta ciertamente muy reducido, sin superar en ningún caso el $4,25 \%$ sobre el total en ambos sexos, y siendo siempre superior entre las hijas que entre los hijos; sino que, además, se constata un sometimiento más férreo a dicha dinámica centrípeta por parte de los vástagos masculinos frente a los femeninos, ya que resulta mayor el porcentaje de hijos solteros varones mayores de 18 años que permanecen en casa, que el de hijas en idéntica situación. Este modelo de reproducción social parece dar prioridad, pues, a cierta actitud proclive al sometimiento disciplinar de la prole a los dictámenes del jefe de casa, quien, para evitar la disgregación patrimonial de los bienes aportados por la dote de su consorte, y asimismo de los gananciales que ambos han ido acumulando a lo largo de sus vidas, ha optado por permitir que se desposen únicamente aquellos hijos o hijas cuyo matrimonio redunde en beneficios objetivos -en la mayoría de las ocasiones también inmateriales - para la casa a la hora de acceder a un reconocimiento sociopolítico mayor en el ámbito local, o de ascender dentro de la jerarquizada división interna que presenta este sector social privilegiado.

No es de extrañar que en las casas hidalgas del interior gallego, los jefes que se hallan al frente de hogares con estructuras familiares extensas y múltiples vivan acompañados de parientes en primer y segundo grado -ascendientes, descendientes y colaterales-, entre los cuales, después de sus propios vástagos, juntamente con sus yernos y nueras, abundan sus hermanos, sus nietos, e incluso sus padres, madres, suegros/as y tíos/as, a los cuales hemos de añadir además sus sobrinos/as ${ }^{52}$. A fin de cuentas, la dureza de este modelo de reproducción social les obligada a ser solidarios con aquellos familiares que habían tenido que sacrificar sus propias voluntades para que la casa se pudiese perpetuar. El hidalgo lugués don Blas María Rubiños así se lo manifestaba perfectamente a su hijo don Vicente, en una carta que le envió en 1806, con el objeto refrescarle la memoria $-\mathrm{y}$ sobre todo la conciencia- recordándole algunas de sus obligaciones, y haciéndole saber que:

"No te digo mas, enttiendelo como debes pues no eres bobo y no puedo ablartte mas claro, (...) ten presente el ser hijo de obedienzia, que a no ser tus pa-

(dirs.): Noblesse française, noblesse hongroise, $X V P$ - $X I X^{e}$ siècles, Budapest, 1981, pp. 35-36 ; y NASSIET, Michael: Noblesse et pavreté. La petite noblesse en Bretagne, XVe-XVIIIe siècle, Bannalec, 1997, pp. 255-273. Y finalmente, en cuarto lugar, en el ámbito británico, Peter Laslett — siguiendo a Lawrerice Stone - ha fijado la edad al primer matrimonio entre la gentry inglesa en torno a los 25 años entre 1558 y 1641 (Cf. Househoid and Familiy in Fast Time, Camdridge, 1978, pp. 154-155); resultando algc más prematura la edad de los nobles escoceses al desposarse en primeras nupcias: 22,5 años en 15601637 y 23,6 durante el siglo XVII, tal como ha demostrado recientemente Brown, Keith M.: Noble Society in Scotland. Wealth, Family and Culture from Reformation to Revolution, Edimburgo, 2000, p. 116.

51 Véase la Tabla 4 del Apéndice estadístico.

52 Véase la Tabla 5 del Apéndice estadístico. 
dres y primero tu tiyo [sic] no eras // sino un bil gusano de la tierra como tu no ignoras sino es que te agas un insinsatto" 53 .

\section{PINCIPALES ELEMENTOS DE LA DINÁMICA DE CASA Y DE LA REPRODUCCIÓN SOCIAL}

Entre los principales elementos de esta dinámica centrípeta, basada en un modelo de reproducción social que pretende someter a los miembros de la familia a un juego de intereses condicionado por la perpetuación de la casa, merece una atención singular el relevo generacional. Este modelo sucesorio impuesto por la lógica de casa no sólo afecta al relevo en la jefatura, sino que va a ir más allá, para condicionar activamente, incluso, a su política matrimonial ${ }^{54}$. Ambos factores, esto es, sistema sucesorio y política matrimonial, actúan en una misma dirección en el seno de las familias hidalgas, y son los verdaderos responsables -junto con la tupida red de influencias políticas que ha tejido la casa en los ámbitos local y comarcal- del rol específico que ha de desempeñar cada pariente biológico en su compromiso personal hacia la casa de procedencia.

En este sentido, ya hemos comprobado como los datos procedentes del Catastro de Ensenada para mediados del siglo xVIII nos sirven para delimitar un modelo familiar en el que prima un tamaño ciertamente amplio, entre 6,5 y 7 miembros; en el cual, pese al predominio de la familia nuclear y de la aparición de algunos vestigios que indican cierto deseo de emancipación familiar -todavía muy tenue-, es evidente la gran impronta de la troncalidad, verificable a través de la presencia de abundantes hogares extensos y múltiples, y también de aquellos que, aún siendo nucleares, se hallan presididos por algún/a viudo/a. En ambos casos, el rol del jefe, dueño o señor de casa, que coincide con la figura jurídica del pater familias, resulta casi infranqueable, y en buena medida esto se debe a que el individuo que ocupa dicho puesto en la jerarquía familiar lo hace porque existe un documento legal, de más o menos antigüedad, pero con vigencia a fin de cuentas, que estipula quiénes han de acceder a dicho cargo, y sobre todo - y he aquí algo que nos gustaría subrayar-, en qué condiciones y cuándo deben de hacerlo ${ }^{55}$.

Sin embargo, el Catastro de Ensenada apenas nos permite ir más allá a la hora de indagar sobre las causas que se derivan de este sistema de reproducción social y, mucho menos, cómo consigue perdurar en la larga duración entre la elite hidal-

53 ACM, Pardo-Montenegro, leg. 39, mazo II, Libro de correspondencia de don Blas Maria Rubiños, ff. 34v.-35r. Véase una transcripción íntegra del libro de correspondencia de dicho hidalgo lugués en PRESECO GaRAZO, A.: «El libro de correspondencia de don Balas María Rubiños (1790-1807): Presentación temática de su contenido y transcripción», CEG, 116 (2003), pp. 131-176.

54 AGo, Roberto: “Ruoli familiari e statuto giuridico", in Quaderni Storici, 88, (1995), pp. 111-133; CASEY, James: The history of the family, Oxford, 1989, pp. 67 ss.; CHACÓN JIMENEZ, F.: “Hacia una nueva..."; Ga.CTo, E.: "El marco..."; y Godoy, Jack: The European Family. An Historico-Antropological Essay, Oxford, 2000, pp. 30-31.

55 Cf. Presedo Garazo, A.: Dueños..., pp. 309-314. 
ga del antiguo reino de Galicia. A lo sumo, además de lo ya enunciado, puede confirmarnos que, en efecto, a mediados del siglo XVIII, el principal contingente de hogares hidalgos se halla bajo la jefatura de varones casados, seguidos, a continuación, de aquellos otros a cuyo frente se encuentra una viuda - en primer lugar-o un viudo ${ }^{56}$. Los dueños siempre dejan sentir su autoridad dentro de la casa en sus diferentes ámbitos de actuación socioeconómica, cultural y relacional, aún después de que se haya disuelto la pareja conyugal que detenta la jefatura tras el óbito de uno de los dos cónyuges. Ora se trate del jefe junto con su consorte femenino, ora de uno/a de ambos ya enviudado/a, su autoridad resulta un elemento singular de este particular sistema de reproducción social, puesto que las expectativas del resto de los miembros de la familia dependen de las decisiones que toma, generalmente aconsejado por algunos parientes que han conseguido acceder a un reconocimiento mayor dentro de este acotado contexto relacional - en ocasiones, excesivamente restrictivo- De ahí que vivan bajo su autoridad, y en ocasiones tutela, entre 2,77 hermanos/as e hijos/as con yernos/nueras en los hogares hidalgos de Arzúa y Melide que cuentan con parentela corresidente, y 3,15 en los de Ourense. E incluyendo al resto de familiares unidos por lazos sanguineos a los dueños, entre 3,18 y 3,83 individuos según nos fijemos en el interior de la provincia de A Coruña o en el extremo noroccidental de la de Ourense; de los cuales, algo más de dos tercios se hallan en estado de soltería.

Los datos catastrales no nos permiten realizar, en cambio, otro tipo de estimaciones que las estrictamente relacionadas con el perfil estructural de los 291 hogares hidalgos; muy útiles, eso sí, para detectar la existencia de una lógica común que parece determinar el futuro del conjunto de la parentela en función de los designios de quienes desempeñan la jefatura. Por lo que, si deseamos comprobar cómo se perpetuó esta dinámica de reproducción social centrípeta y su verdadero alcance durante el Antiguo Régimen gallego, y más concretamente en el siglo XVII, debemos acudir a otras tipologías de fuentes históricas a partir de las cuales podamos realizar el seguimiento pormenorizado de todas y cada una de las distintas generaciones biológicas que se suceden en una serie acotada de casas, basándonos para ello, por un lado, en la metodología de reconstrucción de familias ${ }^{57}, y$, por otro, en la metodología aplicada por Michael Nassiet en su conocido estudio sobre las reconstrucciones genealćgicas de la pequeña nobleza bretona, en el cual dicho autor aboga por incluir la información sociológica como soporte imprescindible en el esquema genealógico de la casa nobiliaria ${ }^{53}$.

Así que, partiendo de la documentación familiar conservada en una serie de archivos privados hidalgos, hemos realizado el seguimiento detallado de todas y cada una de las generaciones biológicas correspondientes a una veintena de casas linajudas cuyos solares originarios se encuentran en la Galicia interior, desde

56 Véase la Tabla 6 del Apéndice estadístico.

57 HenRY, Louis: Manual de demografía histórica, Barcelona, 1983, pp. 105 ss.

${ }^{5 B}$ NASSIET, Michael : :Hisioire sociale et methode lignagere. L'exemple de la petite noblesse de Haute-Bretagne", Histoire, Economie et Societé, Paris, 1990. 
sus comienzos históricos, frecuentemente entre 1550 y 1650 , hasta las primeras décadas del siglo XIX, con la intención de despejar algunas de las dudas que no alcanza a resolver el Catastro de Ensenada ${ }^{59}$.

Los 59 matrimonios de que tenemos constancia documental, entre los cuales se hallan las parejas de jefes, engendraron, de media, una prole compuesta por 3,4 hijos, superando, por tanto, los valores obtenidos a partir del catastro para mediados del XVIII. Se trata de una descendencia extensa, máxime si tenemos en cuenta que esta media de hijos únicamente hace referencia a los vástagos que aparecen citados en la documentación familiar consultada (principalmente testamentos, dotes, arras, donaciones...), esto es, a los que estaban vivos cuando los jefes se refirieron a ellos en el momento en que comenzaron a sentir la necesidad de ir allanando el camino para que el nuevo relevo generacional se efectuase con la menor conflictividad interfamiliar posible. Si tomamos esta media de 3,4 hijos teóricos como el $60 \%$ superviviente del total de hijos engendrados por cada matrimonio, suponiendo que un $40 \%$ de la prole hubiese fallecido previamente, esta media podría haber sido incluso algo mayor, hasta situarse en 5,66 hijos/as ${ }^{60}$. Además, hemos de tener en cuenta que hasta un $45,76 \%$ de estas parejas de dueños tuvieron entre 3 y 5 hijos conocibles ${ }^{61}$.

Un $61,90 \%$ de la prole está compuesta por varones, correspondiéndole un porcentaje bastante menor a las mujeres: un $38,09 \%$. A grandes rasgos, esta proporción confirma la información catastral, si bien es cierto que, en aquella fuente, la preponderancia masculina entre la descendencia resulta menos acusada.

La casa disponía, así, en cada generación biológica, de una media de hijos comprendida entre 3,4 y 5,66 individuos, de los cuales la mayoría eran varones. Lógicamente, para que el modelo reproductivo de la casa se pudiese materializar con éxito habia que desposar ventajosamente a aquellos/as hijos/as cuyo matrimonio pudiese suponer nuevas expectativas de promoción ${ }^{62}$, condenando a la soltería al resto de la descendencia directa en primer grado. O lo que es lo mismo, poner en fun-

59 Cf. Presedo Garazo, A.: Dueños..., cap. III.

60 Muy próxima, por tanto, a los 5,8 hijos/familia de las familias de uun nivel socio-económico algo superior a la media de la jurisdicción" de Xallas durante el siglo XVIII. Cf. BarReiro Mallón, Baudilio: La jurisdicción de Xallas en el siglo XVIII. Población, sociedad y economía, Santiago de Compostela, 1978, p. 186.

61 Exactamente, los datos desglosados según el número de hijos por cada pareja de jefes son los siguientes:

\begin{tabular}{ccc|ccc}
\hline$n .^{\circ}$ de hijos & casos & Total hijos por tramo & n. hijos & casos & Total hijos por tramo \\
\hline 0 & 4 & 0 & 5 & 9 & 45 \\
1 & 11 & 11 & 6 & 4 & 24 \\
2 & 7 & 14 & 7 & 3 & 21 \\
3 & 9 & 27 & 8 & 3 & 24 \\
4 & 9 & 36 & Total & 59 & 202
\end{tabular}

62 Véase sino el análisis que hacen Leonor Davidoff y Catherine Hall en relación con el importante papel que desempeña la tamilia en el proceso de consolidación de las fortunas de la clase media inglesa durante el periodo 1780-1850 (Cf. Family Fortumes. Men and women of the English middlle class, 1780-1850, Londres, 1994, pp. 321 ss.). Cf. además BECKETT, J. V.: The Aristocracy in England, 1660-1914, Oxford, 1986, pp.103-108; y DewalD, Jonathan: The European Nobility, 1400-1800, Cambridge, 1996, pp. $168-176$. 
cionamiento una política matrimonial muy restrictiva. En la media en que el matrimonio operaba en la práctica como un mecanismo efectivo para establecer nuevas alianzas familiares horizontales, que también propiciaban procesos de ascenso social $^{63}$, las hijas fueron puestas en el mercado matrimonial con más asiduidad que los varones (un $64,06 \%$ frente a un $51,92 \%$ ). Es de estas uniones conyugales selectivas de donde van a salir, claro está, las nuevas parejas de dueños que, en el futuro, tendrán que velar para que la casa continúe su andadura según los cauces establecidos en los documentos fundacionales. Por este motivo, el matrimonio de un vástago debía ser pactado lo mejor posible, previamente estudiado, y estar a la altura de las expectativas que la casa había puesto en su exitoso desenlace. Y para ello, era necesario que ésta dispusiese no sólo de un capital material y simbólico considerable ya vinculado, sino también de un patrimonio todavía sin amortizar que estuviese a la altura del precio fijado en los contratos de dote y arras, para que el matrimonio, finalmente, se pudiese llegar a consagrar. De hecho, según la evolución del precio de las dotes de esta veintena de casas hidalgas en el momento de formalizar sus pactos matrimoniales, se ha alcanzado el techo en la primera mitad del siglo XVIII (Gráfico 2).

Gráfico 2. Evolución comparada del precio de las dotes de 20 casas hidalgas, con el de la comarca de Deza, el de la hidalguía de la ciudad de Santiago de Compostela, y el de la Casa de Noceda (en rs.).

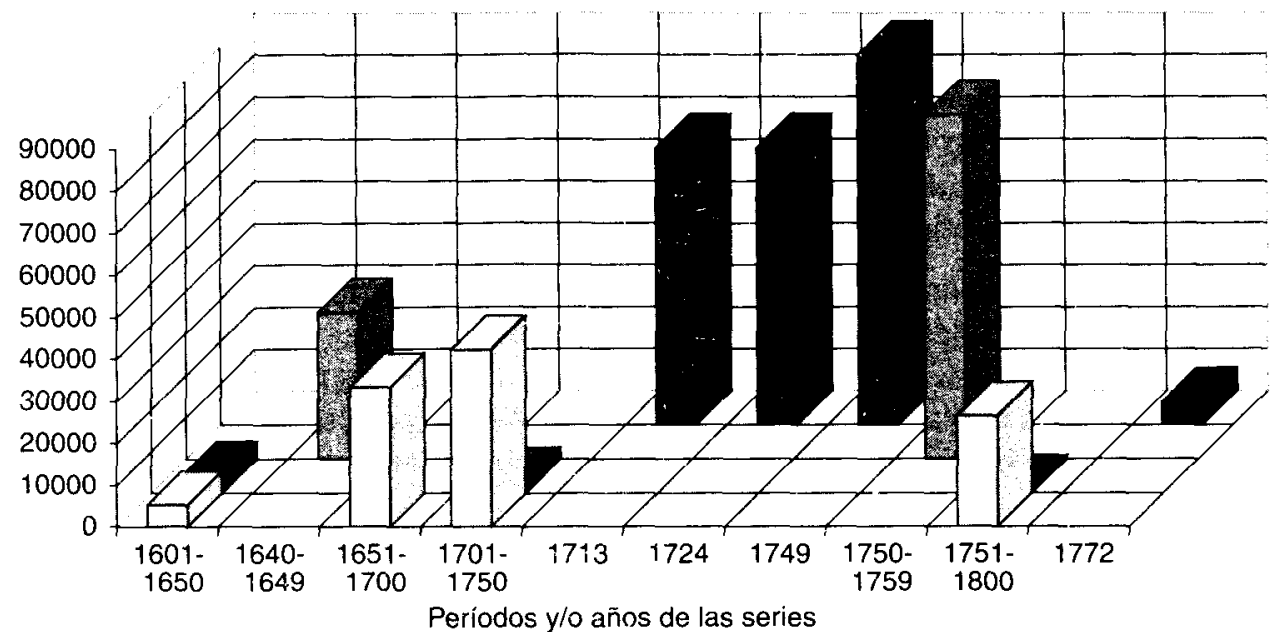

Dotes de 20 casas hidalgas

Dotes hidalguía compostelana

Dotes Deza

Casa de Noceda

Nota: Los datos referidos a las 20 casas hidaigas proceden de Presedo Garazo, A.: Dueños..., p. 290; los de la comarca de Deza han sido calculados a partir de GómEż BuxÁN, César: "La dote matrimonial. Economía y sociedad en Deza durante los siglos XVI a XVII!", Descubrindo Deza. Anuario de Estudios de Investigación, 3 (2001), pp. 3-43; los de la hidalguia de la ciudad de Santiago de Compostela han sido tomados de Burgo LOPEZ, C.: "Niveles sociales y relaciones matrimoniales en Santiago y su comarca (1640-1750), a través de las escrituras de dote", in VV.AA., La Documentación Notarial..., t. I, pp. 197198; y los de la Casa de Noceda, de AHPOu, C.P., Casa do Castro, Noceja, caja 5.

63 Dubert Garcia, I.: Historia..., p. 190; y Migués Rodriguez, V.M.: As terras..., pp. 96-108. 
Para el resto de los hijos, para quienes el matrimonio era poco menos que un estado inimaginable por lo inalcanzable que resultaba al margen del apoyo de la casa, el celibato definitivo se perfilaba como la opción más viable. Al contrario de lo que sucede en el momento de desposar, las hijas solteras pasaban a un segundo plano en comparación con sus homólogos masculinos que tampoco habían accedido al matrimonio, y permanecían en la casa al amparo de los nuevos dueños desempeñando generalmente tareas relacionadas con el servicio ${ }^{64}$. Así, pese a que el porcentaje de hijos solteros era más elevado que el de hijas solteras, con un $48,07 \%$ frente a un $35,93 \%$, las opciones que se le presentaban a estos primeros eran, no obstante, más ventajosas. Hasta un $62 \%$ de estos segundones solteros abrazaban la religión, situándose al frente de curatos parroquiales o entrando en algún cenobio ${ }^{65}, y$, los menos, accediendo a cargos de responsabilidad en la jerarquía eclesiástica de alguna de las cinco mitras gallegas ${ }^{66}$. Unos pocos formaban parte del reducido $8,65 \%$ del total de varones que habían accedido a la milicia con claras opciones de conseguir un cargo militar, sobre todo a medida que avancemos en el siglo $\mathrm{XVIII}{ }^{67}$. E incluso, recientemente, hemos tenido ocasión de demostrar que el mundo académico también resultó una buena opción para aquellos vástagos hidalgos gallegos que buscaban una recolocación futura en la administración civil o eclesiástica ${ }^{68}$.

En cambio, tan sólo un $21,73 \%$-esto es, menos de un cuarto- de las hijas que permanecian solteras el resto de sus vidas disponía de la posibilidad de ingresar en un cenobio ${ }^{69}$. El resto, que equivalía a un mayoritario $78,26 \%$ de las mismas, permanecian en casa. Al no desposarse ni tampoco ingresar en una institución eclesiástica regular, la casa se veía parcialmente desahogada de nuevos desembolsos económicos al evitar el pago de nuevas dotes.

Sólo así, controlando rigurosamente el destirio de los corresidentes, los dueños podían tener la seguridad y la certeza casi absolutas de que se llegaría a perpetuar el patrimonio de la casa, y con él, sobre todo, su posición de preeminencia social que ellos mismos habían heredado de sus antepasados, para ampliarlo incluso con nuevas mejoras vinculares. De hecho, el mayor impulso en la actividad fundacional

64 Cf. Vaquero Lastres, B. M. : “La hidalguía...", p. 55.

65 Ibid., p. 58; y Presedo Garazo, A.: Dueños..., pp. 463-465.

66 De hecho, según ha podido demostrar Arturo Iglesias Castelao al estudiar los 311 expedientes de limpieza de sangre de los eclesiásticos prebendados en la Catedral de Santiago de Compostela entre 1545 y 1752 , hasta un $66,99 \%$ de los mismos eran de procedencia hidalga o hijos y/o nietos de caballeros (Cf. "Análisis sociológico del Cabildo compostelano a través de los expedientes de limpieza de sangre», Compostellanum, XLI-3/4 (1996), p. 437).

$67 \mathrm{Cf}$. Andújar Castrillo, F.: “Aproximación al origen social de los militares en el siglo XVIII (17001724)", Chronica Nova 10, (1979), pp. 13 y 15.

68 Presedo Garazo, A.: “Estudiantes...".

69 Y eso, aún dando por supuesto que habia en Galicia un cenobio femenino prestigioso al que dirigían las casas hidalgas más acomodadas a algunas de sus hijas: el convento de San Paio de Antealtares, en Santiago de Compostela. Sin embargo, la elevada dote de 1.400 ducs., fijada en 1696, resultaba inalcanzable para el grueso principal de la hidalguía gallega (Cf. , M. ColomBÁs, García M.: Las señoras de San Payo. Historia de las Monjas Benedictinas de San Pelayo de Antealtares, Santiago de Compostela, 1980, pp. 195 ss.). 
que protagonizan estas veinte casas todavía acontece entre 1650 y $1750^{70}$, coincidiendo con una etapa en la que, por cierto, también se incrementa el ritmo de acceso a los títulos nobiliarios por parte de la hidalguía gallega en su conjunto ${ }^{71}$.

Poco después de esta etapa expansiva de la propiedad vinculada gallega, basada - en buena medida - en este modelo de reproducción social que se articula a partir de una política matrimonial restrictiva y de un sistema sucesorio no igualitario, cuyos verdaderos garantes eran los jefes de casa, en el tercer cuarto del siglo XVIII, un hidalgo de la comarca de Melide, llamado don Juan Francisco Valeriano Varela y Aguiar, decidió redactar sus Cien discurssos concissos y morales para indicarles a sus hijos cómo debían comportarse. Precisamente, quisiéramos finalizar nuestra reflexión con uno de sus discursos que resume a la perfección, muy expresivamente, la idea fundamental que subyace en dicha dinámica reproductiva:

«En la cassa se ha de oir en grande enojo o pequeño

no mas que la voz del dueño ${ }^{72}$.

70 Presedo Garazo, A.: Garazo, Dueños..., pp. 195-198. Resultados análogos ha obtenido Luis Dominguez Castro para el conjunto de la provincia de Ourense, con una importancia aún mayor de la actividad fundacional durante el siglo xvIII (Cf. "Las tierras...", pp. 129-130).

71 ACuÑa RuBio, Carlos: "Títulos nobiliarios de los hijos de Galicia", Boletín de Estudios de Genealogía, Heráldica y Nobiliaria de Galicia 1, (2002), pp. 37-50.

72 ACF, Libro becerro..., f. 86 r., terceto $n .^{\circ} 89$. 


\section{APÉNDICE ESTADÍSTICO}

Tabla 1. Tamaño medio y estructura por sexos de los hogares hidalgos de las comarcas de Arzúa, Melide y Ourense en 1752

a. Tamaño medio de los hogares

\begin{tabular}{c|ccc|ccc}
\hline \multirow{2}{*}{$\begin{array}{c}n .{ }^{\circ} \text { de } \\
\text { hogares }\end{array}$} & \multicolumn{4}{|c}{ Andividuos contabilizados } & \multicolumn{3}{c}{$n .^{\circ}$ individuos por hogar } \\
\cline { 2 - 7 } & $\begin{array}{c}\text { dueños } \\
\text { familiares }\end{array}$ & $\begin{array}{c}\text { gentes } \\
\text { del servicio }\end{array}$ & Total & $\begin{array}{c}\text { dueños } \\
\text { familiares }\end{array}$ & $\begin{array}{c}\text { gentes } \\
\text { del servicio }\end{array}$ & Total \\
\hline 73 & 289 & 192 & 481 & 3,95 & 2,63 & 6,58 \\
\hline
\end{tabular}

Nota: 1 individuo no determinado.

\section{OURENSE}

\begin{tabular}{|c|c|c|c|c|c|c|}
\hline \multirow{2}{*}{$\begin{array}{c}n .^{\circ} d e \\
\text { hogares }\end{array}$} & \multicolumn{3}{|c|}{ Individuos contabilizados } & \multicolumn{3}{|c|}{ n. individuos por hogar } \\
\hline & $\begin{array}{c}\text { dueños } \\
\text { y familiares }\end{array}$ & $\begin{array}{c}\text { gentes } \\
\text { del servicio }\end{array}$ & Total & $\begin{array}{c}\text { dueños } \\
\text { y familiares }\end{array}$ & $\begin{array}{c}\text { gentes } \\
\text { del servicio }\end{array}$ & Total \\
\hline 218 & 1.069 & 381 & 1.450 & 4,90 & 1,74 & 6,65 \\
\hline
\end{tabular}

NotA: 2 individuos no determinados.

\section{b. Estructura por sexos de los hogares}

\begin{tabular}{|c|c|c|c|c|c|c|c|c|c|c|c|}
\hline \multicolumn{12}{|c|}{ ARZÚA Y MELIDE } \\
\hline \multicolumn{4}{|c|}{ Dueños y familiares } & \multicolumn{4}{|c|}{ Gentes del servicio } & \multicolumn{4}{|c|}{ Total } \\
\hline \multicolumn{2}{|c|}{ varones } & \multicolumn{2}{|c|}{ mujeres } & \multicolumn{2}{|c|}{ varones } & \multicolumn{2}{|c|}{ mujeres } & \multicolumn{2}{|c|}{ varones } & \multicolumn{2}{|c|}{ mujeres } \\
\hline$n .^{\circ}$ & $\%$ & $n .^{\circ}$ & $\%$ & $n^{\circ}$ & $\%$ & $n .^{\circ}$ & $\%$ & $n .^{\circ}$ & $\%$ & $n .^{\circ}$ & $\%$ \\
\hline 149 & 51,55 & 140 & 48,44 & 94 & 48,95 & 98 & 51,04 & 243 & 50,51 & 238 & 49,48 \\
\hline \multicolumn{4}{|c|}{ Parcial: 289} & \multicolumn{4}{|c|}{ Parcial: 192} & \multicolumn{4}{|c|}{ Total: 481} \\
\hline
\end{tabular}

NotA: 1 individuo no determinado.

\section{OURENSE}

\begin{tabular}{|c|c|c|c|c|c|c|c|c|c|c|c|}
\hline \multicolumn{4}{|c|}{ Dueños y familiares } & \multicolumn{4}{|c|}{ Gentes del servicio } & \multicolumn{4}{|c|}{ Total } \\
\hline \multicolumn{2}{|c|}{ varones } & \multicolumn{2}{|c|}{ mujeres } & \multicolumn{2}{|c|}{ varones } & \multicolumn{2}{|c|}{ mujeres } & \multicolumn{2}{|c|}{ varones } & \multicolumn{2}{|c|}{ mujeres } \\
\hline$n .^{\circ}$ & $\%$ & $n .^{\circ}$ & $\%$ & $n .^{\circ}$ & $\%$ & $n .^{\circ}$ & $\%$ & $n .^{\circ}$ & $\%$ & $n .^{\circ}$ & $\%$ \\
\hline 542 & 50,70 & 527 & 49,29 & 183 & 48,03 & 198 & 51,96 & 725 & 50,00 & 725 & 50,00 \\
\hline \multicolumn{4}{|c|}{ Parcial: 1.069} & \multicolumn{4}{|c|}{ Parcial: 381} & \multicolumn{4}{|c|}{ Total: 1.450} \\
\hline
\end{tabular}

Nota: 2 individuos no determinados. 
Tabla 2. Estructuras familiares de las casas hidalgas de las comarcas de Arzúa, Melide y Ourense en 1752

\begin{tabular}{|c|c|c|c|c|}
\hline \multirow{2}{*}{$\frac{\text { Estructuras familiares }}{\text { SOLITARIO: }}$} & \multicolumn{2}{|c|}{ Arzúa y Melide } & \multicolumn{2}{|c|}{ Ourense } \\
\hline & $n .^{\circ}$ & $\%$ & $n .^{\circ}$ & $\%$ \\
\hline Viudos & 3 & 4,10 & 0 & 0,00 \\
\hline Viudas & 2 & 2,73 & 4 & 1,85 \\
\hline Solteros & 3 & 4,10 & 5 & 2,31 \\
\hline Solteras & 4 & 5,47 & 9 & 4,16 \\
\hline Total & 12 & 16,43 & 18 & 8,33 \\
\hline NUCLEAR: & $n .^{\circ}$ & $\%$ & $n .^{\circ}$ & $\%$ \\
\hline Pareja conyugal & 2 & 2,73 & 13 & 6,01 \\
\hline Pareja conyugal + hijos & 16 & 21,91 & 83 & 38,42 \\
\hline Viudo/a + hijos/as (o nietos/as) y yernos/nueras & 18 & 24,65 & 35 & 16,20 \\
\hline Total & 36 & 49,31 & 131 & 60,64 \\
\hline EXTENSO: & $n .^{\circ}$ & $\%$ & $n \cdot{ }^{\circ}$ & $\%$ \\
\hline Ascendiente & 2 & 2,73 & 17 & 7,87 \\
\hline Descendiente & 1 & 1,36 & 6 & 2,75 \\
\hline Colateral & 4 & 5,47 & 24 & 11,11 \\
\hline Ascendiente y colateral & 4 & 5,47 & 7 & 3,24 \\
\hline Descendiente y colateral & 3 & 4,10 & 2 & 0,92 \\
\hline Total & 14 & 19,17 & 56 & 25,92 \\
\hline MÚLTIPLE: & $n^{\circ}$ & $\%$ & n. & $\%$ \\
\hline Ascendiente & 1 & 1,36 & 0 & 0,00 \\
\hline Descendiente & 0 & 0,00 & 4 & 1,85 \\
\hline Colateral & 0 & 0,00 & 0 & 0,00 \\
\hline Descendiente y colateral & 1 & 1,36 & 5 & 2,31 \\
\hline Fréreche & 9 & 12,32 & 2 & 0,92 \\
\hline Total & 11 & 15,06 & 11 & 5,09 \\
\hline
\end{tabular}

Nota: 2 hogares indeterminados en la comarca de Ourense. 
Tabla 3. Estructura por edades y sexos de los hogares hidalgos de las comarcas de Arzúa, Melide y Ourense en 1752

\section{a. Arzúa y Melide}

\begin{tabular}{c|ccc|ccc}
\hline \multirow{2}{*}{ Tramos de edades } & \multicolumn{3}{|c|}{ Varones } & \multicolumn{3}{c}{ Mujeres } \\
\cline { 2 - 7 } & Sol. & Cas. & Viu. & Sol. & Cas. & Viu. \\
\hline menos de 18 & 55 & 0 & 0 & 45 & 0 & 0 \\
\hline $18-24$ & 20 & 1 & 0 & 11 & 2 & 0 \\
\hline $25-39$ & 11 & 12 & 1 & 8 & 5 & 1 \\
\hline $40-49$ & 4 & 6 & 1 & 0 & 6 & 4 \\
\hline $50-80$ & 3 & 13 & 10 & 4 & 5 & 9 \\
\hline $81-95$ & 0 & 0 & 1 & 0 & 0 & 0 \\
\hline Total & 93 & 32 & 13 & 68 & 18 & 14 \\
\hline
\end{tabular}

NOTA: Todos los familiares que aparecen únicamente como "mayores de 18 años" han sido incluidos en el tramo de 18-24 años. No se ha tenido en cuenta los 51 individuos (11 varones y 40 mujeres) cuya edad no ha sido asentada.

\section{b. Ourense}

\begin{tabular}{c|ccc|ccc}
\hline \multirow{2}{*}{ Tramos de edades } & \multicolumn{3}{|c|}{ Varones } & \multicolumn{3}{c}{ Mujeres } \\
\cline { 2 - 7 } & Sol. & Cas. & Viu. & Sol. & Cas. & Viu. \\
\hline menos de 18 & 253 & 1 & 0 & 164 & 0 & 0 \\
\hline $18-24$ & 83 & 7 & 0 & 45 & 10 & 0 \\
\hline $25-39$ & 13 & 51 & 0 & 15 & 39 & 2 \\
\hline $40-49$ & 7 & 43 & 2 & 4 & 13 & 8 \\
\hline $50-80$ & 7 & 41 & 17 & 10 & 15 & 32 \\
\hline $81-95$ & 1 & 0 & 1 & 0 & 0 & 3 \\
\hline Total & 364 & 143 & 19 & 238 & 77 & 45 \\
\hline
\end{tabular}

NotA: Todos los familiares que aparecen únicamente como "mayores de 18 años" han sido incluidos en el tramo de 18-24 años. No se ha tenido en cuenta los 185 individuos (16 varones, 167 mujeres y 2 no determinados) cuya edad no ha sido asentada. 
Tabla 4. Hijos e hijas que cohabitan con los dueños de casa en los hogares de las comarcas de Arzúa, Melide y Ourense en 1752.

a. Arzúa y Melide

\begin{tabular}{|c|c|c|c|c|c|c|c|c|}
\hline \multicolumn{9}{|c|}{ HIJOS } \\
\hline \multicolumn{4}{|c|}{ Solteros } & \multicolumn{4}{|c|}{ Casados para casa } & \multirow{2}{*}{ Total hijos } \\
\hline-18 & +18 & Tot. & $\%$ & -18 & +18 & Tot. & $\%$ & \\
\hline 44 & 15 & 59 & 100 & 0 & 0 & 0 & 0 & 59 \\
\hline \multicolumn{9}{|c|}{ HIJAS } \\
\hline \multicolumn{4}{|c|}{ Solteras } & \multicolumn{4}{|c|}{ Casadas para casa } & \multirow{2}{*}{ Total hijos } \\
\hline-18 & +18 & Tot. & $\%$ & -18 & +18 & Tot. & $\%$ & \\
\hline 44 & 9 & 53 & 98,14 & 0 & 1 & 1 & 1,85 & 54 \\
\hline
\end{tabular}

Nota: Se desconoce la edad exacta de 5 hijos, 9 hijas y 1 individuo indeterminado.

\section{b. Ourense}

\begin{tabular}{|c|c|c|c|c|c|c|c|c|}
\hline \multicolumn{9}{|c|}{ HIJOS } \\
\hline \multicolumn{4}{|c|}{ Solteros } & \multicolumn{4}{|c|}{ Casados para casa } & \multirow{2}{*}{ Total hijos } \\
\hline-18 & +18 & Tot. & $\%$ & -18 & +18 & Tot. & $\%$ & \\
\hline 225 & 68 & 293 & 97,34 & 1 & 7 & 8 & 2,65 & 301 \\
\hline \multicolumn{9}{|c|}{ HIJAS } \\
\hline \multicolumn{4}{|c|}{ Solteras } & \multicolumn{4}{|c|}{ Casadas para casa } & \multirow{2}{*}{ Total hijos } \\
\hline-18 & +18 & Tot. & $\%$ & -18 & +18 & Tot. & $\%$ & \\
\hline 139 & 41 & 180 & 95,74 & 0 & 3 & $3+5$ & 4,25 & 188 \\
\hline
\end{tabular}

Nota: Se desconoce la edad exacta de 2 hijos y 82 hijas ( 5 de ellas casadas). 
Tabla 5. Parentela corresidente en las casas hidalgas de las comarcas de Arzúa, Melide y Ourense en 1752

\begin{tabular}{l|cc|cc}
\hline \multirow{2}{*}{ Grado de Parentesco } & \multicolumn{2}{|c|}{ Arzúa y Melide } & \multicolumn{2}{c}{ Ourense } \\
\cline { 2 - 5 } & $n^{\circ}$ & $\%$ & $n .^{\circ}$ & $\%$ \\
\hline Padres, suegros/as y tíos/as & 7 & 3,72 & 13 & 1,81 \\
\hline Hermanos/as y cuñados/as & 43 & 22,87 & 44 & 6,12 \\
\hline Hijos/as y yernos/nueras & 121 & 64,36 & 590 & 82,17 \\
\hline Sobrinos/as & 10 & 5,31 & 11 & 1,53 \\
\hline Nietos/as y sobrinos-nietos/as & 5 & 2,65 & 49 & 6,82 \\
\hline Bisnietos/as & 0 & 0,00 & 3 & 0,41 \\
\hline Indeterminados & 2 & 1,06 & 8 & 1,11 \\
\hline Total & 188 & 100,00 & 718 & 100,00 \\
\hline
\end{tabular}

Tabla 6. Jefaturas de las casas hidalgas de las comarcas de Arzúa, Melide y Ourense según el sexo y estado civil en 1752

\section{a. Arzúa y Melide}

\begin{tabular}{|c|c|c|c|c|c|c|c|c|c|}
\hline \multicolumn{6}{|c|}{ Varones } & \multicolumn{4}{|c|}{ Mujeres } \\
\hline \multicolumn{2}{|c|}{ solteros } & \multicolumn{2}{|c|}{ casados } & \multicolumn{2}{|c|}{ viudos } & \multicolumn{2}{|c|}{ solteras } & \multicolumn{2}{|c|}{ viudas } \\
\hline$n .^{\circ}$ & 13 & $n .^{\circ}$ & 27 & $n .^{\circ}$ & 12 & $n .^{\circ}$ & 5 & $n .^{\circ}$ & 16 \\
\hline $\begin{array}{c}\% \text { total } \\
\text { hidalgos (1) }\end{array}$ & 8,72 & $\begin{array}{l}\% \text { total } \\
\text { hidalgos }\end{array}$ & 18,12 & $\begin{array}{l}\% \text { total } \\
\text { hidalgos }\end{array}$ & 8,05 & $\begin{array}{c}\% \text { total } \\
\text { hidalgas (4) }\end{array}$ & 3,57 & $\begin{array}{c}\% \text { total } \\
\text { hidalgas }\end{array}$ & 11,42 \\
\hline $\begin{array}{c}\% \text { total } \\
\text { hogares (2) }\end{array}$ & 17,80 & $\begin{array}{c}\% \text { total } \\
\text { hogares }\end{array}$ & 36,98 & $\begin{array}{c}\% \text { total } \\
\text { hogares }\end{array}$ & 16,43 & $\begin{array}{c}\% \text { total } \\
\text { hogares }(5)\end{array}$ & 6,84 & $\begin{array}{c}\% \text { total } \\
\text { hogares }\end{array}$ & 21,91 \\
\hline $\begin{array}{c}\% \text { con } \\
\text { jefatura } \\
\text { masculina (3) }\end{array}$ & 25,00 & $\begin{array}{l}\% \text { con } \\
\text { jefatura } \\
\text { masculina }\end{array}$ & 51,92 & $\begin{array}{c}\% \text { con } \\
\text { jefatura } \\
\text { masculina }\end{array}$ & 23,07 & $\begin{array}{c}\% \text { con } \\
\text { jefatura } \\
\text { femenina }(6)\end{array}$ & 23,80 & $\begin{array}{c}\% \text { con } \\
\text { jefatura } \\
\text { femenina }\end{array}$ & 76,19 \\
\hline
\end{tabular}

NoTA: $1=149$ varones hidalgos; 2 y $5=73$ hogares; $3=52$ hogares; $4=140$ mujeres hidalgas; y $6=21$ hogares. 


\section{b. Ourense}

\begin{tabular}{|c|c|c|c|c|c|c|c|c|c|}
\hline \multicolumn{6}{|c|}{ Varones } & \multicolumn{4}{|c|}{ Mujeres } \\
\hline \multicolumn{2}{|c|}{ solteros } & \multicolumn{2}{|c|}{ casados } & \multicolumn{2}{|c|}{ viudos } & \multicolumn{2}{|c|}{ solteras } & \multicolumn{2}{|c|}{ viudas } \\
\hline$n .^{o}$ & 15 & $n .^{\circ}$ & 130 & $n^{\circ}$ & 21 & $n^{\circ}$ & 10 & $n .^{\circ}$ & 42 \\
\hline $\begin{array}{c}\% \text { total } \\
\text { hidalgos (1) }\end{array}$ & 2.76 & $\begin{array}{c}\% \text { total } \\
\text { hidalgos }\end{array}$ & 23,98 & $\begin{array}{l}\% \text { total } \\
\text { hidalgos }\end{array}$ & 3,87 & $\begin{array}{c}\% \text { total } \\
\text { hidalgas (4) }\end{array}$ & 1,89 & $\begin{array}{l}\% \text { total } \\
\text { nidalgas }\end{array}$ & 7,69 \\
\hline $\begin{array}{c}\% \text { total } \\
\text { hogares }(2)\end{array}$ & 6,88 & $\begin{array}{l}\% \text { total } \\
\text { hogares }\end{array}$ & 59,63 & $\begin{array}{l}\% \text { total } \\
\text { hogares }\end{array}$ & 9,63 & $\begin{array}{c}\% \text { total } \\
\text { hogares (5) }\end{array}$ & 4,58 & $\begin{array}{c}\% \text { total } \\
\text { hogares }\end{array}$ & 19,26 \\
\hline $\begin{array}{c}\% \text { con } \\
\text { jefatura } \\
\text { masculina (3) }\end{array}$ & 9,03 & $\begin{array}{c}\% \text { con } \\
\text { jefatura } \\
\text { masculina }\end{array}$ & 78,31 & $\begin{array}{c}\% \text { con } \\
\text { jefatura } \\
\text { masculina }\end{array}$ & 12,65 & $\left\{\begin{array}{c}\% \text { con } \\
\text { jefatura } \\
\text { femenina }(6)\end{array}\right.$ & 19,23 & $\begin{array}{c}\% \text { con } \\
\text { jefatura } \\
\text { femenina }\end{array}$ & 80,76 \\
\hline
\end{tabular}

NOTA: $1=542$ varones hidalgos; 2 y $5=218$ hogares; $3=166$ hogares; $4=527$ mujeres hidalgas; y $6=52$ hogares 